\title{
Redução das desigualdades regionais na alocação dos recursos federais para a saúde
}

\author{
Reduction of the regional inequalities in the \\ allocation of the federal resources for the health
}

\footnotetext{
1 Secretário de Assistência à Saúde do M inistério da Saúde, Esplanada dos M inistérios, Bloco G, edifício sede, sala 901 , 70058-900, Brasília DF. renilson@saude.gov.br
}

\begin{abstract}
This article is about the strategies developed by Brazilian M inistery of $\mathrm{H}$ ealth to change the patterns of health financing in the country. In the beginning of its introduction, the new $\mathrm{N}$ ational Health System (SUS) kept the old way of health financing, wich was used by the social welfare system. O nce this system had to serve its contributors, the most part of the health funds was destinated to the most developed regions of the country, which concentrate a biggest number of workers included in the social welfare. To solve this, the M inistery of $\mathrm{H}$ ealth adopted new kinds of fund distribution. The poorest regions share began proportionally biggest than the richest ones. As a result of this strategy, the differences of funds among regions became shorter, and its also possible to conclude that the services suply raised in the poorest regions of the country.
\end{abstract}

Key words Financing, Inequality, $\mathrm{H}$ ealth assistance
Resumo 0 artigo trata das estratégias do $\mathrm{M} \mathrm{i-}$ nistério da Saúde para mudar o padrão de financiamento da saúde no Brasil. No início da implantação do Sistema Ú nico de Saúde, manteve-se a lógica de financiamento do antigo sistema, baseado na prestação de assistência aos beneficiados da previdência social. I sso concentrava os recursos nas regiões do país mais desenvolvidas economicamente, e que possuíam uma rede de servi ços mais estruturada. Como solução, foram adotadas novas modalidades de repasse financeiro. Para aquelas regiões menos favorecidas, os repasses passaram a ser proporcionalmente maiores. A estratégia resultou numa diminuição das diferenças regionais nos valores alocados pelo gestor federal para a saúde, com números que também apresentam indícios de uma maior expansão da oferta de serviços de saú de nas regiões mais pobres.

Palavras-chave Financiamento, Desigualdade, Assistência à saúde 


\section{Redução das desigualdades regionais na alocação dos recursos federais para a saúde}

Um passo significativo para o cumprimento da diretriz constitucional de construção do Sistema Ú nico de Saúde com direção única em cada esfera de governo foi a transferência do Instituto $\mathrm{N}$ acional de Assistência M édica da Previdência Social (Inamps) do M inistério da Previdência eAssistência Social (M PAS) para o M inistério da Saúde. Esse ato teve efeito com a publicação do decreto n. 99.060, de 7 de março de 1990, antes, portanto, da promulgação da lei n. 8.080, que só ocorreu em setembro do mesmo ano. Assim, o M inistério da Saúde iniciou a implantação do SUS tendo o Inamps como base do novo sistema.

Para assegurar a continuidade, agora em caráter universal, da assistência médico-hospitalar a ser prestada à população, o papel exercido pelo Inamps e a participação do Ministério da Previdência no financiamento do mesmo foram inicialmente preservados. 0 Inamps somente foi extinto pela lei n. 8.689, de 27 de julho de 1993, quase três anos após a promulgação da Lei Orgânica da Saúde (8.080/90).

No parágrafo único do seu artigo primeiro, a lei que o extinguiu estabelecia que: As funções, competências, atividades e atribuições do Inamps serão absorvidas pelas instâncias federal, estadual e municipal gestoras do Sistema Ú nico de Saúde, de acordo com as respectivas competências, critérios e demais disposi ções das leis n. 8.080, de 19 de setembro de 1990 , en. 8.142 , de 28 de de zembro de 1990.

Ao se preservar o Inamps, preservou-se também a sua lógica de financiamento e de alocação de recursos financeiros. Dessa forma, o SUS iniciou sua atuação na área da assistência à saúde com caráter universal, utilizando-se, porém, de uma instituição que tinha sido criada e organizada para prestar assistência a um segmento específico da população.

U ma das conseqüências dessa preservação foi o estabelecimento de limites físicos e financeiros para as unidades federadas segundo a lógica do I namps, o que garantiria a manutenção da situação até então vigente. 0 u seja, 0 SUS não adotou uma lógica própria para financiar a assistência à saúde de toda a população, o que significaria um grande remanejamento da alocação de recursos entre os estados. Essa medida, sem dúvida, geraria uma forte reação política dos estados mais desenvolvi- dos e que contavam com uma maior proporção de recursos.

Porém, a manutenção do I namps e de sua lógica de financiamento não evitou que, a partir de maio de 1993, portanto pouco antes da sua extinção (em 27 de julho de 1993), o M inistério da Previdência Social deixasse de repassar recursos da previdência social, criando uma enorme defasagem entre a nova responsabilidade constitucional e a disponibilidade orçamentária. Os anos de 1993 e de 1994 foram de grandes dificuldades para o SUS, pela total falta de recursos para honrar os compromissos resultantes das definições da Constituição Federal e da Lei Orgânica da Saúde.

A partir de 1998, as estratégias utilizadas pelo M inistério da Saúde em relação ao financiamento foram:

a) busca de mais recursos;

b) fontes estáveis de financiamento para a saúde;

c) distribuição mais eqüitativa dos recursos entre os estados da Federação.

Em relação aos dois primeiros itens ( $a$ e b), sua análise não é objeto deste artigo. Vale registrar, porém, o incremento de recursos financeiros alocados no orçamento do Ministério da Saúde, que passou de R\$17.120.238.461,00 em 1997, para $R \$ 22.598 .227 .190,00$ em 2001, representando um crescimento de $31,9 \%$. Também foi significativa a promulgação da Emenda Constitucional n. 29, em 2000, possibilitando a garantia de recursos estáveis para o financiamento do SUS. A seguir, serão analisadas as alterações realizadas pelo M inistério da Saúde em relação ao terceiro item (c).

$\mathrm{N}$ a busca da ampliação dos tetos financeiros, apresentava-se 0 argumento de que havia uma má distribuição de recursos entre os diversos estados, que ben eficiaria aqueles mais ricos em detrimentos daqueles mais pobres. Essa argumentação tomava por referência, sistematicamente, os recursos disponibilizados para a assistência médico-hospitalar, sem levar em conta, entre outros elementos, o tamanho e o nível de complexidade da rede de assi stência à saúde ou os recursos disponibilizados para a aten ção básica, a vigilância epidemiológica e o controle de doenças.

Para que se possa melhor entender a atual alocação de recursos, é necessário rever a sua origem. Antes do SUS, a grande atuação do poder público na área da saúde dava-se por intermédio do Instituto Nacional da Previdência Social (INPS) e, depois, do Inamps, que eram au- 
tarquias do M PAS. N aquela época, os brasileiros estavam divididos em três categorias quanto à assistência à saúde, a saber: os que podiam pagar; os que tinham direito à assistência prestada pelo I namps (trabalhadores com carteira assinada); e os não-contribuintes, estes sem direito algum à saúde.

A distribuição dos recursos gastos pelo Inamps entre as regiões do Brasil era bastante desigual, conforme se vê na tabela 1.

À epoca, todas as ações nas áreas de promoção à saúde e prevenção de doenças eram custeadas pelo M inistério da Saúde. Os gastos do Inamps referidos na tabela 1 eram os relativos à área de assistência médico-hospitalar, com um perfil bastante semelhante e comparável ao que temos hoje na área de assistência de média e alta complexidades, diferenciando-se, evidentemente, pela incorporação de novos procedimentos não disponíveis então.

Pode-se verificar que a região Sudeste- com $43,79 \%$ da população e $59,28 \%$ dos recursos foi a que recebeu, proporcionalmente, mais re cursos, e que as regiões $\mathrm{N}$ orte e $\mathrm{N}$ ordeste foram as que menos receberam.

Esses dados são importantes para podermos visualizar a concretização da estratégia de redução das desigualdades no financiamento para as várias regiões do país.

Acrescentem-se a esses dados os limites financeiros dos estados, já na vigência da Constituição de 1988 e da Lei Orgânica da Saúde. A tabela 2 demonstra que, em 1994, ainda havia de si gualdades na al ocação dos recursos do M inistério da Saúde. Em 1994 não se fazia a distinção entre o financiamento da A tenção Básica e da M édia e Alta Complexidades. Os valores dos te tos financeiros contemplavam, segundo a série de portarias que os regulamentou, todos os procedimentos catalogados nos sistemas de informação ambulatorial e hospitalar (SIA e SIH), agentes comunitários de saúde e medicamentos excepcionais.

Esses tetos financeiros foram estabelecidos tendo por referência, ainda, a série histórica de gastos do Inamps e, por conseqüência, a capacidade instalada nos estados. Essa lógica manteve as desigualdades anteriores e, desse modo, observa-se que os menores valores per capita são os dos estados do Norte e do N ordeste, sendo os mais baixos os do Acree do Amapá, com $R \$ 25,00$, seguidos do Amazonas com $R \$ 26,84$, de Roraima com $R \$ 27,49$ e de Sergipe com $R \$ 28,66$.

Os dados apresentados mostram que os recursos financei ros para custeio das atividades assistenciais foram extremamente influenciados pela concentração da capacidade instalada de hospitais, clínicas e laboratórios que serviam à população assistida pela previdência social. Dessa forma, os recursos destinados aos estados com maior desenvolvimento econômico e social (regiões Sul e Sudeste) foram, por décadas, de valores muito superiores aos das regiões Norte, N ordeste e Centro-O este.

\section{Implantação do modo de financiamento per capita}

A partir de março de 1998, com a edição da portaria n. 2.121/GM , é implantado o Piso da Atenção Básica (PAB). Com o PAB, passa-se a dispor do modo de financiamento tendo por base o per capita, além do modo já existente de compra de serviço com base na oferta. Para tanto, foi feita a divisão do teto financeiro contemplando:

- Atenção Básica;

- Assistência de M édia e Alta Complexidade Ambulatorial e H ospitalar.

$O$ PAB de cada município é calculado tendo por base um valor per capita e transferido de forma automática, "fundo a fundo". Substituise a forma anterior de financiamento por prestação de serviços pela lógica de transferência de recursos. Com essa nova lógica o município passa, em contrapartida, a assumir a responsabilidade sanitária pelo nível de atenção básica.

Os recursos do $P A B$ também foram divididos em $P A B$ fixo e PAB variável. Enquanto os recursos do $P A B$ fixo são transferidos tendo por base 0 valor per capita, o valor do PAB variável depende da adesão do município a programas prioritários definidos pelo M inistério da Saúde, tais como os Programas de Agentes Comunitários de Saúde, de Saúde da Família e de Combate às $\mathrm{C}$ arências N utricionais; e pelas ações estratégicas, tais como a Farmácia Básica e as Ações Básicas de Vigilância Sanitária.

O M anual da Atenção Básica, aprovado pela portaria GM /M S n. 3.925, de 13 de novembro de 1998, define essa área assistencial como o conjunto de ações, de caráter individual ou coletivo, situadas no primeiro nível de atenção dos sistemas de saúde, voltadas para a promoção da saúde, a prevenção de agravos, o tratamento e a reabilitação. E frisa, ainda, que essas ações não se limitam àquel es procedimentos incluídos no Grupo de Assistência Básica da tabela do SIA/SU S, quando da implantação do Piso da Atenção Bá- 
Tabela 1

Inamps: desigualdades regionais no gasto com assistência médica. Brasil, 1986

\begin{tabular}{lcc}
\hline Regiões & Gastos sobre despesa corrente \% total & População da região sobre o total (\%) \\
\hline Norte & 2,27 & 5,48 \\
Nordeste & 18,10 & 28,82 \\
Sudeste & 59,28 & 43,79 \\
Sul & 15,14 & 15,12 \\
Centro-Oeste & 5,02 & 6,78 \\
Brasil & 100,00 & 100,00 \\
\hline
\end{tabular}

Fonte: Inamps - Secretaria de Planejamento/DIS, 1987.

Tabela 2

Limites financeiros anuais e respectivos valores per capita por UF. 1994

\begin{tabular}{|c|c|c|c|}
\hline Unidade Federada & População & Teto financeiro anual & $\begin{array}{l}\text { Valor per capita } \\
\text { (Em } R \$ 1,00)\end{array}$ \\
\hline Tocantins & 987.248 & 32.942 .472 & 33,37 \\
\hline Pará & 4.805 .432 & 149.593 .080 & 31,13 \\
\hline Rondônia & 1.263 .146 & 37.166 .100 & 29,42 \\
\hline Roraima & 245.255 & 6.741 .312 & 27,49 \\
\hline Amazonas & 2.256 .227 & 60.549 .744 & 26,84 \\
\hline Acre & 445.126 & 11.128 .152 & 25,00 \\
\hline Amapá & 314.152 & 7.853 .796 & 25,00 \\
\hline Norte & 10.316 .586 & 305.974 .656 & 29,66 \\
\hline Ceará & 6.664 .536 & 279.230 .868 & 41,90 \\
\hline Piauí & 2.703 .942 & 109.449 .312 & 40,48 \\
\hline Paraíba & 3.331 .728 & 134.322 .144 & 40,32 \\
\hline M aranhão & 5.177 .941 & 205.876 .248 & 39,76 \\
\hline Pernambuco & 7.423 .000 & 290.062 .692 & 39,08 \\
\hline Rio Grande do Norte & 2.547 .230 & 96.378 .900 & 37,84 \\
\hline Alagoas & 2.649 .929 & 86.130 .984 & 32,50 \\
\hline Bahia & 12.492 .757 & 396.399 .624 & 31,73 \\
\hline Sergipe & 1.578 .739 & 45.243 .900 & 28,66 \\
\hline Nordeste & 44.569 .802 & 1.643 .094 .672 & 36,87 \\
\hline Distrito Federal & 1.702 .350 & 89.457 .444 & 52,55 \\
\hline Goiás & 4.244.392 & 196.575 .528 & 46,31 \\
\hline M ato Grosso & 2.215 .969 & 97.971 .528 & 44,21 \\
\hline M ato Grosso do Sul & 1.882 .488 & 69.932 .328 & 37,15 \\
\hline Centro-0este & 10.045 .199 & 453.936 .828 & 45,19 \\
\hline São Paulo & 33.273 .183 & 1.922 .548 .584 & 57,78 \\
\hline Rio de Janeiro & 13.294 .472 & 688.443 .396 & 51,78 \\
\hline M inas Gerais & 16.427 .747 & 770.165 .076 & 46,88 \\
\hline Espírito Santo & 2.745 .854 & 96.201 .288 & 35,03 \\
\hline Sudeste & 65.741 .256 & 3.477 .358 .344 & 52,89 \\
\hline Paraná & 8.738 .669 & 464.729 .112 & 53,18 \\
\hline Rio Grande do Sul & 9.534 .727 & 483.864 .780 & 50,75 \\
\hline Santa Catarina & 4.779 .434 & 213.764 .064 & 44,73 \\
\hline Sul & 23.052 .830 & 1.162 .357 .956 & 50,42 \\
\hline Brasil & 153.725 .673 & 7.042 .722 .456 & 45,81 \\
\hline
\end{tabular}

Fonte: SAS/M S. Valores em R $\$ 1,00$ 
sica. A ampliação desse conceito se torna necessária para avançar na direção de um sistema de saúde centrado na qualidade de vida das pessoas e de seu meio ambiente.

Com a portaria GM/M S n. 2.121/98, que define os recursos federais para a atenção básica, assistência ambulatorial de média e alta complexidade e assistência hospitalar para os estados e municípios, o M inistério da Saúde concretizou o primeiro e significativo passo para a construção de um sistema de saúde voltado para a atenção das pessoas, e não para a doença. Um sistema quenão seja reduzido ape nas ao componente da assistência médica. Ao mesmo tempo em que se deu um passo importante no sentido de formatar um modelo de atenção mais abrangente, avançou-se no processo de redução das desigualdades regionais em relação ao financiamento.

A tabela 3, comparativa do valor per capita efetivamente aplicado em 1997 em ações de
Atenção Básica (Grupo de Assistência Básica da tabela do SIA/SU S) com o valor do PAB (fixo + variável) aplicado em 1998, comprova essa afirmativa. 0 incremento de recursos chega em al guns estados a mais de $100 \%$ e incide sobre aqueles que tradicionalmente obtinham menos recursos.

Pode-se observar que, entre 1997 e 1998, o valor per capita teve incremento abaixo da média nacional (34,72\%) nos estados de Minas Gerais, M ato Grosso, São Paulo, Piauí e Rio de Janeiro, e chegou a diminuir no Estado do Paraná $(-1,71 \%)$. Por outro lado, os maiores percentuais de aumento foram dos seguintes estados:

- Bahia-116,71\%

- Pará- 109,03\% e

- Espírito Santo - 106,80\%

Porém, maior do quea redistribuição de recursos que ocorreu entre os estados foi a que ocorreu entre os municípios de um mesmo estado, já que vários municípios não recebiam

\section{Tabela 3}

Teto financeiro anual e valor per capita por UF - Atenção Básica. 1997/1998

\begin{tabular}{|c|c|c|c|c|c|c|}
\hline \multirow[t]{2}{*}{ UF } & \multicolumn{2}{|c|}{1997} & \multicolumn{3}{|c|}{1998} & \multirow{2}{*}{$\begin{array}{c}\text { Variação (\%) per } \\
\text { capita } 97 / 98\end{array}$} \\
\hline & Valor & per capita & PAB fixo & PAB variável & per capita & \\
\hline$\overline{A C}$ & 3.793 .285 & 7,58 & 5.027 .261 & 1.923 .902 & 13,28 & 75,10 \\
\hline $\mathrm{AL}$ & 31.903 .496 & 11,98 & 30.238 .541 & 15.474 .706 & 16,76 & 39,88 \\
\hline$A M$ & 15.740 .211 & 6,40 & 24.628 .993 & 5.790 .865 & 11,82 & 84,84 \\
\hline$A P$ & 3.572 .340 & 8,89 & 4.262 .033 & 1.224 .373 & 12,80 & 43,99 \\
\hline BA & 82.996 .848 & 6,53 & 129.042 .941 & 56.003 .302 & 14,15 & 116,71 \\
\hline CE & 83.733 .478 & 12,10 & 76.142 .977 & 44.163 .155 & 16,91 & 39,73 \\
\hline DF & 16.577 .926 & 8,83 & 18.770 .150 & 7.326 .528 & 13,32 & 50,86 \\
\hline ES & 16.943 .918 & 5,94 & 28.825 .491 & 7.449 .728 & 12,28 & 106,80 \\
\hline GO & 40.003 .768 & 8,62 & 48.705 .746 & 11.227 .930 & 12,39 & 43,69 \\
\hline MA & 53.312 .434 & 10,07 & 60.068 .696 & 25.946 .309 & 15,81 & 57,04 \\
\hline MG & 214.452 .884 & 12,69 & 193.978.958 & 48.116 .497 & 13,91 & 9,65 \\
\hline MS & 17.551 .991 & 8,93 & 19.800 .539 & 6.019 .785 & 12,69 & 42,07 \\
\hline $\mathrm{MT}$ & 29.132 .811 & 12,73 & 26.828 .859 & 7.203 .194 & 14,35 & 12,70 \\
\hline PA & 37.562 .259 & 6,65 & 57.585 .204 & 23.981 .998 & 13,90 & 109,03 \\
\hline PB & 37.490 .961 & 11,25 & 36.637 .354 & 15.744 .938 & 15,37 & 36,60 \\
\hline PE & 90.953 .660 & 12,18 & 89.358 .518 & 34.580 .731 & 16,22 & 33,20 \\
\hline $\mathrm{PI}$ & 35.377 .364 & 13,12 & 33.201 .750 & 13.553 .201 & 16,97 & 29,34 \\
\hline$P R$ & 127.037 .069 & 13,90 & 109.377 .081 & 19.366 .007 & 13,66 & $-1,71$ \\
\hline RJ & 115.809 .930 & 8,54 & 139.569 .855 & 20.355 .316 & 11,44 & 33,92 \\
\hline RN & 27.972 .890 & 10,78 & 27.315 .271 & 12.372 .369 & 14,88 & 37,96 \\
\hline RO & 12.455 .619 & 9,92 & 13.437 .397 & 5.168 .209 & 14,33 & 44,48 \\
\hline $\mathrm{RR}$ & 2.369 .433 & 9,31 & 2.585 .575 & 854.371 & 12,95 & 39,10 \\
\hline RS & 61.923 .733 & 6,34 & 98.388 .839 & 19.128 .612 & 11,66 & 83,86 \\
\hline SC & 42.446 .585 & 8,56 & 51.426 .469 & 12.802 .740 & 12,53 & 46,33 \\
\hline SE & 20.340 .071 & 12,27 & 20.406 .950 & 8.602 .352 & 16,97 & 38,27 \\
\hline SP & 339.525 .818 & 9,77 & 364.723 .289 & 34.184 .612 & 11,06 & 13,20 \\
\hline TO & 10.538 .536 & 9,75 & 11.799 .745 & 4.884 .251 & 14,82 & 51,95 \\
\hline Brasil & 1.571 .519 .318 & 9,84 & 1.722 .134 .482 & 463.449 .981 & 13,26 & 34,72 \\
\hline
\end{tabular}


nenhum recurso federal para a saúde, antes do PAB.

No entanto, a maciça habilitação dos municípios em Gestão Plena da Atenção Básica, que representou um avanço do ponto de vista da responsabilização de milhares de gestores municipais e uma distribuição mais equilibrada de recursos por meio da implantação do $\mathrm{PAB}$, não assegurou necessariamente a qualidade e efetividade da atenção básica em todos os municípios, nem foi suficiente para garantir 0 acesso de todos os cidadãos aos demais níveis de atenção.

U ma investigação mais aprofundada poderia avaliar os efeitos da mudança no modelo de gestão e na distribuição de recursos em termos do aumento de eqüidade no acesso à saúde.

\section{Alocação de novos recursos federais para o custeio da Assistência de Média eAlta Complexidade}

Também na área da Assistência de M édia e Alta Complexidade, nos últimos anos, notadamente a partir de 1998, o ministério, conforme estratégia definida, procurou alocar os recursos novos de forma a gradualmente reduzir as desigualdades entre os per capita das unidades federadas.

Até então, a alocação de recursos respondia à capacidade instalada. $\mathrm{Na}$ época do financiamento da assistência médico-hospitalar pelo Inamps, a alocação de recursos era maior onde havia mais trabal hadores formais, ou seja, contribuintes, e, conseqüentemente, nas regiões com uma economia mais desenvolvida, que também eram as regiões com os serviços de saúde mais estruturados. A nova estratégia do $\mathrm{M} \mathrm{i-}$ nistério da Saúde foi a de alocar todo recurso novo para custeio da assistência médico-hospitalar em proporções maiores onde o per capita era menor e e vice-versa. Dentro dessa estraté gia do ministério, também estava a compreensão de que uma maior quantidade de recursos para custeio estimularia maiores investimentos, tanto do setor público quanto do privado.

Essa estratégia redistributiva pode ser observada na tabela 4, comparativa dos valores de fevereiro de 1998 e setembro de 2002.

Em fevereiro de 1998, o per capita de São Paulo (o maior do país) foi de $R \$ 46,18$, ou seja, 3,65 vezes maior que o do Amapá (o menor do país), quefoi de $R \$ 12,65$. Em dezembro de 2001, o per capita do Rio de Janeiro (então o maior do país) foi de $\mathrm{R} \$ 79,04$ e o do Amapá (o menor), de $\mathrm{R} \$ 39,80$. A diferença entre o maior e o menor passou de 3,65 vezes em 1998 para apenas 2,14 vezes em 2002. A redução da diferença entre os estados foi resultado da aplicação dos novos recursos obtidos pelo M inistério da Saúde, não tendo significado remanejamento de recursos entre estados.

É importante ressaltar, analisando a tabela 4, que essa alteração somente foi possível com a firme determinação de reduzir as desigualdades regionais no gasto com assistência. Enquanto o incremento de recursos financeiros para a Assistência de M édia e Alta Complexidade, de 1998 a 2002, foi de $82,60 \%$ na média brasileira, no estado do Amapá foi de 203,27\%, no Acre, $132,07 \%$, somente para citar alguns exemplos.

Embora a região Sul, dadas as considerações feitas anteriormente, ainda detenha o maior valor per capita, seguida da região Sudeste, podese notar que as diferenças, que ainda persistem, não são mais tão gritantes. Por exemplo: em 1998, a diferença entre o per capita da região Sudeste em relação à Norte atingia 105,29\%. Em 2002, baixou para $61,25 \%$. A mesma coisa pode ser observada em relação à região N ordeste, cujo per capita passou de $R \$ 28,49$, em 1998 , para $R \$ 56,54$, em 2002 , com uma variação positiva de $98,46 \%$. Fica demonstrado claramente que as regiões $\mathrm{N}$ orte, $\mathrm{N}$ ordeste e Centro-O este tiveram variações maiores que a média nacional (Tabela 4).

$\mathrm{Na}$ tabela 5 é possível comparar os recursos do limite financeiro com a população de cada região do país no ano de 2001. É de se destacar que se passa a ter uma coerência entre os limites financeiros e a população de cada macrorregião. Enquanto o teto financeiro do CentroO este representa $6,81 \%$ do total dos recursos do Brasil, sua população representa $6,85 \%$ do total do país. Do Nordeste, $27,08 \%$ dos recursos e $28,12 \%$ da população brasileira. Da região Norte, $6,43 \%$ dos recursos e $7,62 \%$ da população. Da região Sudeste, $44,16 \%$ dos recursos e $42,62 \%$ da população. E da região Sul, $15,52 \%$ dos recursos e $14,79 \%$ da população.

A tabela 6 apresenta um comparativo entre os anos de 1994 e 2001 dos limites financeiros anuais, por macrorregião. N essa mesma tabela é possível observar a evolução do percentual do per capita de cada região em relação ao per capita Brasil. Se do ponto de vista do valor absoluto todas as regiões do país tiveram crescimento, do ponto de vista proporcional algumas regiões receberam mais que outras. 0 percen- 
Tabela 4

Limites financeiros da média e alta complexidade por Estado da Federação. 1998/2002

\begin{tabular}{|c|c|c|c|c|c|}
\hline UF & $\begin{array}{l}\text { Limite financeiro mensal } \\
\text { (MAC) fevereiro/1998 }\end{array}$ & per capita & $\begin{array}{l}\text { Limite financeiro mensal } \\
\text { (MAC) setembro/2002 }\end{array}$ & per capita & $\begin{array}{c}\text { Variação } \\
(\%)\end{array}$ \\
\hline$A P$ & 443.581 & 12,65 & 1.651 .289 & 38,36 & 203,27 \\
\hline$A C$ & 781.344 & 18,24 & 2.070 .426 & 42,33 & 132,07 \\
\hline TO & 2.328 .139 & 25,22 & 5.540 .663 & 55,08 & 118,42 \\
\hline PA & 9.463 .295 & 19,69 & 22.931 .612 & 42,64 & 116,55 \\
\hline AM & 4.245 .725 & 20,21 & 10.711 .456 & 43,40 & 114,74 \\
\hline $\mathrm{RR}$ & 453.284 & 20,86 & 1.218 .467 & 42,15 & 102,08 \\
\hline RO & 2.653 .136 & 24,95 & 5.626 .143 & 47,15 & 88,99 \\
\hline Norte & 20.368 .504 & 20,59 & 49.750 .056 & 44,21 & 114,66 \\
\hline SE & 3.365 .880 & 23,97 & 8.434 .070 & 54,82 & 128,72 \\
\hline $\mathrm{BA}$ & 26.839 .513 & 25,06 & 63.516 .651 & 57,21 & 128,29 \\
\hline$A L$ & 6.150 .800 & 27,46 & 14.174 .064 & 58,90 & 114,51 \\
\hline $\mathrm{PI}$ & 6.397 .454 & 28,28 & 13.122 .180 & 54,33 & 92,12 \\
\hline PB & 8.184 .707 & 29,29 & 16.242 .203 & 55,77 & 90,40 \\
\hline CE & 17.873 .161 & 30,58 & 36.829 .290 & 57,74 & 88,81 \\
\hline MA & 12.229 .684 & 27,4 & 24.156 .857 & 49,95 & 82,30 \\
\hline $\mathrm{PE}$ & 21.102 .807 & 33,66 & 40.817 .575 & 60,58 & 79,99 \\
\hline RN & 6.616 .484 & 30,25 & 12.860 .284 & 54,10 & 78,83 \\
\hline Nordeste & 108.760 .490 & 28,49 & 230.153 .174 & 56,54 & 98,47 \\
\hline MS & 5.589 .992 & 33,61 & 12.246 .989 & 68,65 & 104,27 \\
\hline $\mathrm{MT}$ & 5.944 .520 & 30,59 & 13.004 .066 & 59,91 & 95,85 \\
\hline DF & 6.051 .401 & 37,75 & 13.171.301 & 73,66 & 95,12 \\
\hline GO & 12.895 .311 & 32,62 & 26.229 .998 & 60,41 & 85,19 \\
\hline Centro-Oeste & 30.481 .224 & 33,27 & 64.652 .354 & 64,11 & 92,71 \\
\hline RJ & 47.354 .810 & 41,54 & 100.745 .989 & 82,10 & 97,65 \\
\hline ES & 7.318.889 & 30,33 & 15.229 .615 & 57,08 & 88,20 \\
\hline MG & 52.450 .781 & 36,81 & 96.035 .209 & 62,82 & 70,67 \\
\hline SP & 135.782 .950 & 46,18 & 247.419 .653 & 77,77 & 68,40 \\
\hline Sudeste & 242.907 .430 & 42,27 & 459.430 .466 & 74,05 & 75,20 \\
\hline SC & 15.126 .409 & 36,1 & 28.849 .182 & 62,63 & 73,48 \\
\hline RS & 36.193 .816 & 44,02 & 66.204 .649 & 76,33 & 73,39 \\
\hline PR & 31.404 .620 & 40,7 & 57.332 .304 & 70,22 & 72,52 \\
\hline Sul & 82.724 .845 & 41,10 & 152.386 .135 & 71,06 & 72,90 \\
\hline Brasil & 485.242 .493 & 35,99 & 956.372 .185 & 65,72 & 82,60 \\
\hline
\end{tabular}

Fonte: SAS/M S. Valores em R $\$ 1,00$

tual do valor per capita da região N orte em relação ao Brasil, que era $64,75 \%$ em 1994 , passou a $84,44 \%$ em 2001 . 0 da região Nordeste era de $80,48 \%$ em 1994 e passou a $96,30 \%$ em 2001. Já o percentual do per capita da região Sudeste decresceu de 115,46\% em 1994 para $103,60 \%$ em 2001. Como pode ser observado na figura 1 , os valores percentuais de todas as regiões apresentaram uma tendência de aproximação entre si, de 1994 a 2001, evidenciando uma distribuição de recursos mais eqüânime.

Finalmente, a tabela 7 apresenta a perspectiva de diminuiçãao das desigual dades na distri- buição regional dos recursos oriundos do $\mathrm{M} \mathrm{i}$ nistério da Saúde. Devemos destacar o incremento de recursos repassados às regiões $C$ entro-O este, que passa de 5,02\% em 1986 para 6,81\% em 2001; Nordeste, de 18,10\% em 1986 para 27,08\% em 2001; e N orte, de 2,27\% para $6,42 \%$. Esse aumento se dá em detrimento da região Sudeste, que passa de 59,28\% em 1986 para 44,16\% em 2001. 
Tabela 5

Limites financeiros anuais e respectivos valores per capita (atenção básica + M AC), por região - 2001

\begin{tabular}{lrrrrr}
\hline Região & \multicolumn{2}{c}{ Teto financeiro anual } & per capita & \multicolumn{2}{c}{ População } \\
\hline Centro-Oeste & 943.541 .553 & $6,81 \%$ & 81,26 & 11.611 .491 & $6,85 \%$ \\
Nordeste & 3.752 .980 .437 & $27,08 \%$ & 78,69 & 47.679 .381 & $28,12 \%$ \\
Norte & 891.762 .739 & $6,43 \%$ & 68,89 & 12.919 .949 & $7,62 \%$ \\
Sudeste & 6.119 .327 .906 & $44,16 \%$ & 84,67 & 72.262 .411 & $42,62 \%$ \\
Sul & 2.150 .966 .268 & $15,52 \%$ & 85,79 & 25.071 .211 & $14,79 \%$ \\
Brasil & 13.858 .578 .903 & $100,00 \%$ & 81,72 & 169.544 .443 & $100,00 \%$
\end{tabular}

Fonte: SAS/M S. Valores em R $\$ 1,00$

Tabela 6

Comparativo entre os limites financeiros anuais e respectivos valores per capita (Atenção Básica + M AC), por região - 1994/2001

\begin{tabular}{lcccccc}
\hline Regiões & $\begin{array}{c}\text { Teto financeiro } \\
\text { anual }\end{array}$ & $\begin{array}{c}\mathbf{1 9 9 4} \\
\text { Valor } \\
\text { per capita }\end{array}$ & $\begin{array}{c}\text { Percentual do } \\
\text { per capita região } \\
\text { em relação ao } \\
\text { per capita Brasil }\end{array}$ & $\begin{array}{c}\text { Teto financeiro } \\
\text { anual }\end{array}$ & $\begin{array}{c}\mathbf{2 0 0 1} \\
\text { Valor } \\
\text { per capita }\end{array}$ & $\begin{array}{c}\text { Percentual do } \\
\text { per capita região } \\
\text { em relação ao } \\
\text { per capita Brasil }\end{array}$ \\
\hline Centro-O este & 453.936 .828 & 45,19 & 98,65 & 943.541 .553 & 81,26 & 99,41 \\
N ordeste & 1.643 .094 .672 & 36,87 & 80,48 & 3.752 .980 .437 & 78,71 & 96,30 \\
N orte & 305.974 .656 & 29,66 & 64,75 & 891.762 .739 & 69,02 & 84,44 \\
Sudeste & 3.477 .358 .344 & 52,89 & 115,46 & 6.119 .327 .906 & 84,68 & 103,60 \\
Sul & 1.162 .357 .956 & 50,42 & 110,06 & 2.150 .966 .268 & 85,79 & 104,96 \\
Brasil & 7.042 .722 .456 & 45,81 & 100,00 & 13.858 .578 .903 & 81,74 & 100,00 \\
\hline
\end{tabular}

Fonte: SAS/M S. Valores em R $\$ 1,00$

\section{Criação do FAEC}

Em abril de 1999 o M inistério da Saúde criou o Fundo de Ações Estratégicas e de Compensação (FAEC), por meio da portaria GM /M S 531/99. 0 objetivo foi o de garantir o financiamento, pelo gestor federal, de procedimentos de alta complexidade em pacientes com referência interestadual ou procedimentos decorrentes de ações consideradas estratégicas pelo M inistério da Saúde.

Antes da criação do FAEC, a totalidade dos recursos federais destinados ao custeio da assistência à saúde estava al ocada nos tetos financeiros dos estados e do Distrito Federal. Dessa forma, o M inistério da Saúde não dispunha de instrumentos que lhe possibilitassem financiar e priorizar ações consideradas estratégicas.

A ções estratégicas decorrem de políticas de saúde definidas em função das necessidades de grupos prioritários, como é o caso da preven- ção do câncer de colo de útero no âmbito da saúde da mulher, ou da necessidade de ampliação do acesso aos serviços de saúde ofertados à população, a exemplo das campanhas de cirurgias eletivas (catarata, próstata, etc). Essas ações apresentavam uma grande demanda reprimida, em virtude da prioridade dada pelos gestores estaduais e municipais à utilização dos recursos financeiros dos seus tetos para outros procedimentos considerados mais urgentes.

Além disso, o fundo também possibilitou a criação de uma Câmara de Compensação e, posteriormente, a Central Nacional de Regulação da Alta Complexidade, destinada a financiar os procedimentos de alta complexidade realizados em um estado, em pacientes provenientes de outros estados on de esses serviços não são oferecidos.

Os recursos disponíveis para o pagamento dos procedimentos incluídos no FAEC não estão contidos nos tetos financeiros dos estados $e$ 
Figura 1

Evolução do percentual do per capita por região em relação ao per capita Brasil - 1994/2001

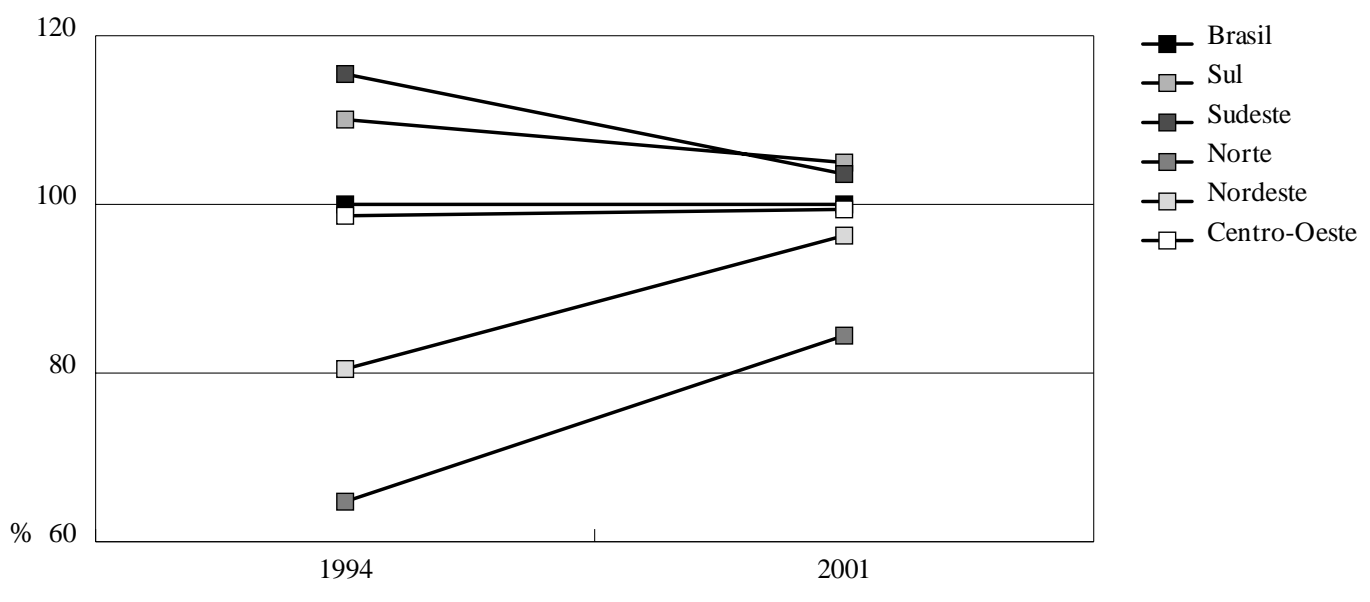

Fonte: SAS/M S

\section{Tabela 7}

Inamps vs. SUS: diminuição das desigual dades na distribuição regional dos recursos para a assistência à saúde, por regiões. 1986/2001

\begin{tabular}{lrrrr}
\hline Regiões & \multicolumn{2}{c}{$\%$ dos recursos } & \multicolumn{2}{c}{$\%$ da população } \\
& 1986 & 2001 & 1986 & 2001 \\
\hline Centro-Oeste & $5,02 \%$ & $6,81 \%$ & $6,78 \%$ & $6,85 \%$ \\
N ordeste & $18,10 \%$ & $27,08 \%$ & $28,82 \%$ & $28,12 \%$ \\
Norte & $2,27 \%$ & $6,42 \%$ & $5,48 \%$ & $7,62 \%$ \\
Sudeste & $59,28 \%$ & $44,16 \%$ & $43,79 \%$ & $42,62 \%$ \\
Sul & $15,14 \%$ & $15,52 \%$ & $15,12 \%$ & $14,79 \%$ \\
Brasil & $100,00 \%$ & $100,0 \%$ & $100,00 \%$ & $100,00 \%$ \\
\hline
\end{tabular}

Fonte: SAS/M S 2001. Valores em $\mathrm{R} \$ 1,00$

municípios. Funcionam, portanto, como recursos "extrateto". O pagamento pelos serviços tanto pode ser feito por meio do Fundo Estadual ou M unicipal de Saúde, como diretamente pelo M inistério da Saúde aos prestadores de serviços ao SUS, de acordo com a modalidade de gestão dos estados e municípios.

0 fundo também tem servido para o financiamento de procedimentos de al to custo, a exemplo dos transplantes que, pelo seu grande impacto financeiro, apresentavam restrições na sua autorização pelos respectivos gestores. Além disso, os novos procedimentos incluídos na Tabela do SUS, e que não dispõem de uma previ- são de seu impacto financeiro, são temporariamente financiados pelo M S, por meio do FAEC, até que se tenha uma série histórica dos seus custos, permitindo a sua transferência fundo a fundo para os tetos estaduais e municipais, ou alocação do valor correspondente no teto do estado. Esse instrumento já foi utilizado para a inclusão, entre outros, da Gastroplastia e do tratamento cirúrgico da Epilepsia.

A iniciativa do ministério em criar o FAEC foi, a princípio, interpretada por al guns gestores estaduais e municipais como uma estratégia de "recentralização" dos recursos da assistência e só não foi inviabilizada porque contou 
com novos recursos federais para a sua implementação. Esses gestores, até então responsáveis pela alocação da totali dade dos recursos federais em seus estados e municípios dentro de seus tetos financeiros, viram com muita preocupação a introdução de um mecanismo de financiamento assumido diretamente pelo ministério.

Em abril de 1999, no momento de sua instituição, o fundo recebeu a sua primeira dotação orçamentária, de $\mathrm{R} \$ 105$ milhões, valor equivalente $1,23 \%$ dos "tetos" financeiros de média e alta complexidade para os estados e o Distrito Federal, fixados em $R \$ 8,5$ bilhões naquele mês.

Em dezembro de 1999 os recursos do FAEC atingiram $\mathrm{R} \$ 406,3$ milhões, representando $4,22 \%$ do total dos "tetos" dos estados e do Distrito Federal, que somaram $\mathrm{R} \$ 9,61$ bilhões, para financiamento da média e alta complexidade.

Em dezembro de 2001 os recursos do fundo totalizaram $\mathrm{R} \$ 1,08$ bilhão, representando $10,58 \%$ dos recursos disponibilizados nos "tetos" dos estados e do Distrito Federal, da ordem de R $\$ 10,2$ bilhões. Em setembro de 2002, os recursos totalizaram $\mathrm{R} \$ 2,19$ bilhões, representando $19,08 \%$ dos recursos disponibilizados nos "tetos" dos estados e do Distrito Federal, da ordem de $R \$ 11,47$ bilhões.

Esse aumento deve-se fundamentalmente à transferência da Terapia Renal Substitutiva para o FAEC, deixando de onerar os tetos dos estados e municípios. Foram retirados dos tetos financeiros R \$773 milhões ealocados R \$77 miIhões de recursos novos totalizando $\mathrm{R} \$ 850 \mathrm{mi}-$ Ihões.

É importante ressaltar que, no período compreendido entre 1999-2002, houve um acréscimo de recursos de $\mathrm{R} \$ 1,86$ bilhão no financiamento da assistência de média e alta complexidade, dos quais $R \$ 1,78$ milhão foram para 0 FAEC.

Como exemplo, destacamos o financiamento dos medicamentos excepcionais, que em janeiro de 2000 era de $R \$ 228,1$ milhões, incluído nos "tetos" dos estados e do Distrito Federal e, ao ser transferido para o FAEC, recebeu recursos adicionais "extrateto" da ordem de R $\$ 161,6$ milhões em 2001, totalizando R $\$ 389,7$ milhões. Em 2002 foram transferidos mais de $R \$ 480,0$ milhões, representando um aumento de $110,5 \%$ no financiamento dessa ação assistencial.

A pós várias mudanças, decorrentes da busca da mel hor maneira de sua utilização, em de zembro de 2001, a destinação dos recursos do FAEC pelo M inistério da Saúde estava dividi- da em quatro grandes blocos de ações financiadas.

a) Ações Assistenciais Estratégicas - ações assistenciais voltadas para grupos populacionais prioritários e para a ampliação de acesso dos usuários do SUS aos procedimentos com grande demanda reprimida, definidas em função de políticas de saúde estabelecidas pelo M inistério da Saúde:

- Campanhas de cirurgias el etivas (catarata, próstata, varizes);

- Transplantes;

- Cirurgias para correção de deformidades craniofaciais;

- M edicamentos excepcionais;

- Kit para carga viral para diagnóstico da Aids;

- Reagentes para diagnóstico da Aids;

- Cirurgia bariátrica (gastroplastia);

- Diagnóstico do câncer de colo uterino;

- Incentivo para Alta Curado do paciente com tuberculose;

- Terapia renal substitutiva.

b) Incentivos - recursos adicionais transferidos de forma complementar ao modo de financiamento decorrente da compra de serviços para estimular a parceria com o sistema público ou a realização de ações assistenciais:

- INTEGRASUS - para os hospitais filantrópicos;

- Incentivo para os estados e municípios para a descentralização das unidades assistenciais da Funasa;

- Incentivo para a assistência hospitalar às populações indígenas.

c) N ovas Ações Programáticas - novos procedimentos incluídos no SUS que, pela impossibilidade de previsão de impacto financeiro ou por depender de adesão progressiva dos gestores, são alocados no FAEC, buscando garantir a sua plena execução, sendo, após a consolidação de um perfil de gasto, incorporado aos "tetos" dos estados e do Distrito Federal:

- Humanização do parto;

- Triagem neonatal;

- Assistência ao portador de deficiência física;

- Assistência ao portador de transtornos decorrentos do uso de álcool e drogas.

d) Central Nacional de Regulação da Alta Complexidade - recursos alocados no FAEC destinados ao financiamento de procedimentos de alta complexidade para usuários do SUS, realizados em pacientes provenientes de outros estados que não dispõem desses serviços.

A figura 2 apresenta a evolução do montante de recursos alocados no FAEC no período. 
Figura 2

Evolução dos recursos do FAEC de 1999 a 2002

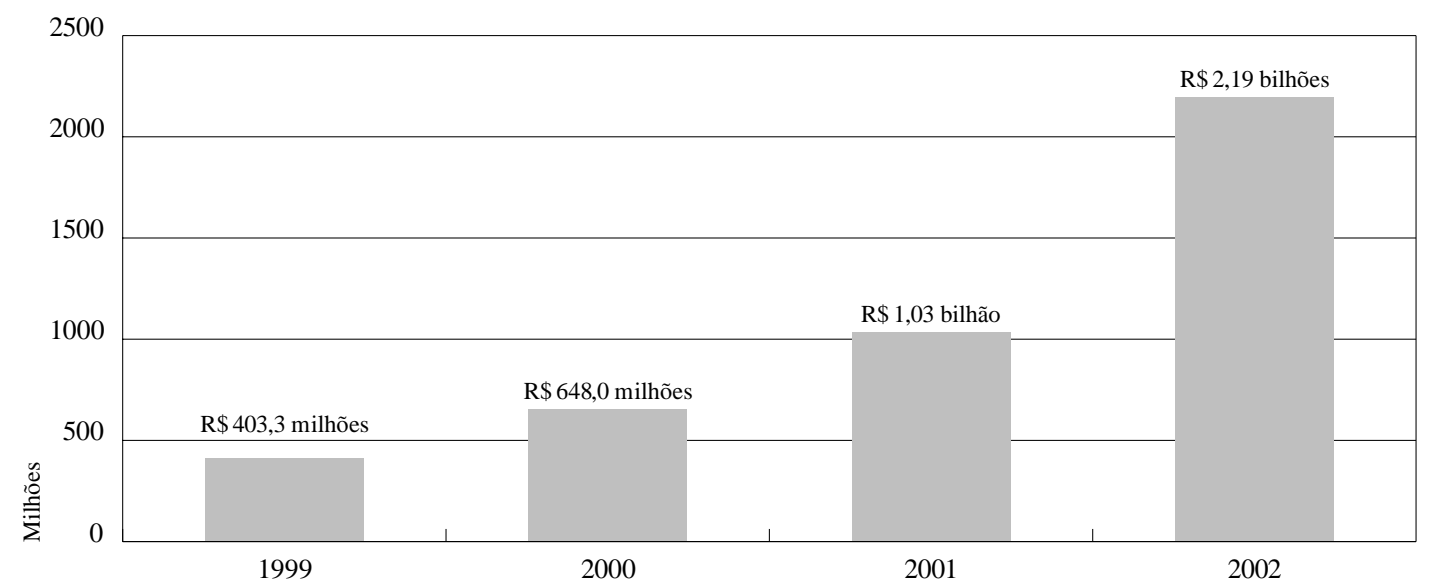

Fonte: SAS/MS

Essa evolução deve-se, em parte, à alocação de novos recursos disponibilizados pelo MS, e em parte a recursos retirados dos tetos estaduais e municipais em comum acordo com esses gestores e aprovação da Comissão Intergestores Tripartite (CIT), como foi o caso dos medicamentos excepcionais.

A prática vem demonstrando que o FAEC tem sido um importante instrumento de implementação de serviços que resultam na ampliação de acesso; e tem funcionado como instrumento de redução de desigualdades regionais, uma vez que remunera os serviços executados, independentemente da procedência do paciente, com recursos não incluídos nos tetos financeiros anteriormente estabel ecidos para cada estado.

H oje o FAEC é reconhecido pelos gestores dos três níveis de governo como um importante instrumento de implementação de políticas e existe uma demanda dos estados e municípios para que o M S inclua outros procedimentos nesse mecanismo de financiamento, mesmo que para tanto seja necessária a retirada dos recursos respectivos dos atuais tetos financeiros. 0 exemplo mais recente desse movimento é o da Terapia Renal Substitutiva (TRS), que vem apresentando grande crescimento, o que tem tornado inviável a sua gestão pelos estados e municípios.

\section{A estratégia de financiamento redistributivo ea expansão da oferta de serviços}

A estratégia do M inistério da Saúde de redução das diferenças regionais na alocação de recursos federais implicou uma expansão na oferta de serviços de saúde também diferenciada regional mente. Há diversos resultados que ilustram essa expansão diferenciada. Como exemplo, apresentamos a evolução dos gastos e do número de internações hospitalares em cada região e em todo o país entre 1997 e 2002 (Tabelas 8 e 9 ).

As tabelas 8 e 9 mostram que houve aumento dos gastos com internação hospitalar em todo o país, mas que nas regiões N orte, N ordeste e Centro-O este esse incremento foi maior. Quanto ao número de internações pode-se verificar que, a despeito de uma diminuição na média nacional no período de 1997 a 2002, houve crescimento significativo na regiões $\mathrm{N}$ orte e Centro-O este.

Um estudo mais aprofundado poderá revelar a real adequação de tal expansão às realidades locais, com conseqüentes conclusões sobre a promoção de eqüidade no sistema de saúde brasileiro. 
Tabela 8

Gasto anual com internação hospitalar por região, 1997 a 20021

\begin{tabular}{|c|c|c|c|c|c|c|c|}
\hline Região & 1997 & 1998 & 1999 & 2000 & 2001 & 2002 & $\begin{array}{c}\text { Variação } \\
(\%)\end{array}$ \\
\hline Norte & 172.672 .522 & 187.648 .598 & 227.709 .006 & 256.639 .770 & 266.384 .458 & 274.816 .770 & 59,2 \\
\hline Centro-Oeste & 271.637 .312 & 287.595 .739 & 318.100 .881 & 343.584 .105 & 367.016 .882 & 374.598 .408 & 37,9 \\
\hline Nordeste & 953.864 .239 & 998.042 .525 & 1.127 .711 .880 & 1.199 .197 .158 & 1.239 .154 .828 & 1.267 .302 .929 & 32,9 \\
\hline Sul & 744.922 .892 & 772.212 .083 & 889.026 .827 & 893.284 .012 & 949.869 .522 & 979.880 .307 & 31,5 \\
\hline Sudeste & 1.848 .403 .406 & 1.886 .846 .953 & 2.171.293.792 & 2.194 .109 .943 & 2.275 .156 .079 & 2.337 .581 .454 & 26,5 \\
\hline Brasil & 3.991 .500 .370 & 4.132 .345 .898 & 4.733 .842 .385 & 4.886 .814 .988 & 5.097 .581 .769 & 5.234 .179 .868 & 31,1 \\
\hline
\end{tabular}

1 Projecãa setembro de 2002.

Fonte: SAS/MS

Tabela 9

Freqüência anual de internações hospitalares por região, 1997 a 20021

\begin{tabular}{|c|c|c|c|c|c|c|c|}
\hline Região & 1997 & 1998 & 1999 & 2000 & 2001 & 2002 & $\begin{array}{c}\text { Variação } \\
(\%)\end{array}$ \\
\hline Centro-O este & 839.894 & 870.563 & 899.485 & 922.811 & 943.401 & 954.274 & 13,62 \\
\hline Norte & 834.104 & 851.754 & 926.080 & 916.706 & 903.839 & 912.343 & 9,38 \\
\hline N ordeste & 3.584 .433 & 3.601 .730 & 3.675 .078 & 3.695 .254 & 3.624 .236 & 3.639 .564 & 1,54 \\
\hline Sul & 2.043 .821 & 2.020 .358 & 2.051 .764 & 2.042 .060 & 2.020 .034 & 1.983 .689 & $-2,94$ \\
\hline Sudeste & 5.049 .212 & 4.904 .227 & 4.885 .969 & 4.849 .306 & 4.736 .145 & 4.752 .705 & $-5,87$ \\
\hline Brasil & $12.351 .464,00$ & $12.248 .632,00$ & $12.438 .376,00$ & $12.426 .137,00$ & $12.227 .655,00$ & $12.242 .574,86$ & $-0,88$ \\
\hline
\end{tabular}

1 Projeção setembro de 2002.

Fonte: SAS/M S

\section{Referências bibliográficas}

Brasil. M inistério da Saúde. Secretaria de Assistência à Saúde 2002. Relatório de Gestão SAS quadriênio 19982001. Editora MS. Brasília.

Souza RR 2002. 0 sistema público de saúde brasileiro. Se minário Internacional Tendências e D esafios dos Sistemas de Saúde nas Américas. São Paulo.

Artigo apresentado em 30/11/2002

A provado em 10/12/2002

Versão final apresentada em 20/12/2002 